$$
\text { CONF-970663-4 SANO97-13UC }
$$

\title{
CALCULATION OF DENSITY AND PERMEABILITY OF COMPACTED CRUSHED SALT WITHIN AN ENGINEERED SHAFT SEALING SYSTEM
}

by:

Marc Loken and William Statham

KEYWORDS

Crushed Salt

Creep Consolidation

Permeability

Pore Pressure

Dislocation Creep

Fluid Flow

Deformation Mechanisms

WIPP

Shaft Sealing

Dynamic Compaction

\section{DISCLAIMER}

This report was prepared as an account of work sponsored by an agency of the United States Government. Neither the United States Government nor any agency thereof, nor any of their employees, makes any warranty, express or implied, or assumes any legal liability or responsibility for the accuracy, completeness, or usefulness of any information, apparatus, product, or process disclosed, or represents that its use would not infringe privately owned rights. Reference herein to any specific commercial product, process, or service by trade name, trademark, manufacturer, or otherwise does not necessarily constitute or imply its endorsement, recommendation, or favoring by the United States Government or any agency thereof. The views and opinions of authors expressed herein do not necessarily state or reflect those of the United States Government or any agency thereof.

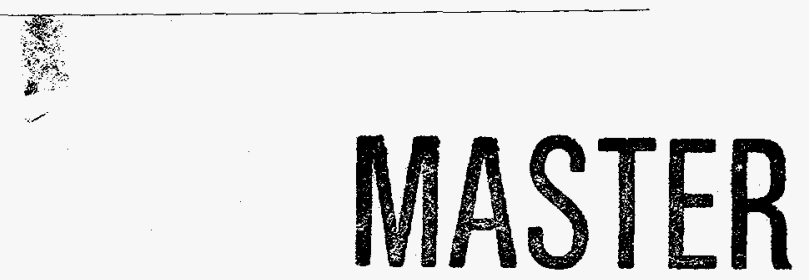




\section{DISCLAMIER}

Portions of this document may be illegible in electronic image produets. Images are produced from the best available original document. 


\title{
Calculation of Density and Permeability of Compacted Crushed Salt Within an Engineered Shaft Sealing System
}

\author{
Marc Loken, Member \\ William Statham ${ }^{2}$
}

\section{Abstract}

Crushed salt from the host Salado Formation is proposed as a sealing material in one component of a multicomponent seal system design for the shafts of the Waste Isolation Pilot Plant (WIPP), a mined geological repository for storage and disposal of transuranic radioactive wastes located near Carlsbad, New Mexico. The crushed salt will be compacted and placed at a density approaching 90 percent of the intact density of the host Salado salt. Creep closure of the shaft will further compact the crushed salt over time, thereby reducing the crushed-salt permeability from the initial state and creating an effective long-term seal. A structural model and a fluid flow model have been developed to provide an estimate of crushed-salt reconsolidation rate as a function of depth, time, and pore pressure. Model results are obtained in terms of crushed-salt permeability as a function of time and depth within the salt column. Model results indicate that average salt column permeability will be reduced to $3.3 \times 10^{-20} \mathrm{~m}^{2}$ in about 100 years, which provides for an acceptable long-term seal component.

\section{Introduction}

The U.S. Department of Energy plans to dispose of transuranic wastes at the Waste Isolation Pilot Plant located in southeastem New Mexico. The WIPP is designed to be a full-scale geologic repository located in the bedded salt of the Salado Formation at a depth of about $655 \mathrm{~m}$ below ground surface. Access to the facility is provided through four vertical shafts. Because these shafts comprise direct communication between lithologic units and connect the underground facility

\footnotetext{
1 RESSPEC Inc., 3824 Jet Drive, Rapid City, South Dakota 57701

2 Intera Inc., 6850 Austin Center Boulevard, Austin, Texas 78731
} 
to the surface, they will be sealed to limit the release of contaminants from the repository and to limit brine flow into the facility.

Figure 1 shows a conceptual shaft seal system for the WIPP Air Intake Shaft (AIS). One of the primary seal components in the Salado Formation is composed of compacted crushed Salado salt. Crushed salt has been selected as a seal material because of its chemical compatibility with the host rock and because it will consolidate with time. Consolidation will occur due to creep of the host rock salt into the shaft and is accompanied by a reduction in permeability of the crushed-salt seal. If the creep consolidation is unimpeded by backstresses developed in the seal, it will eventually reach an extremely low permeability state and be essentially indistinguishable from the host rock. This paper investigates the processes which impact the consolidation of a seal emplaced in the WIPP shaft, and predicts the permeability reduction in the seal as a

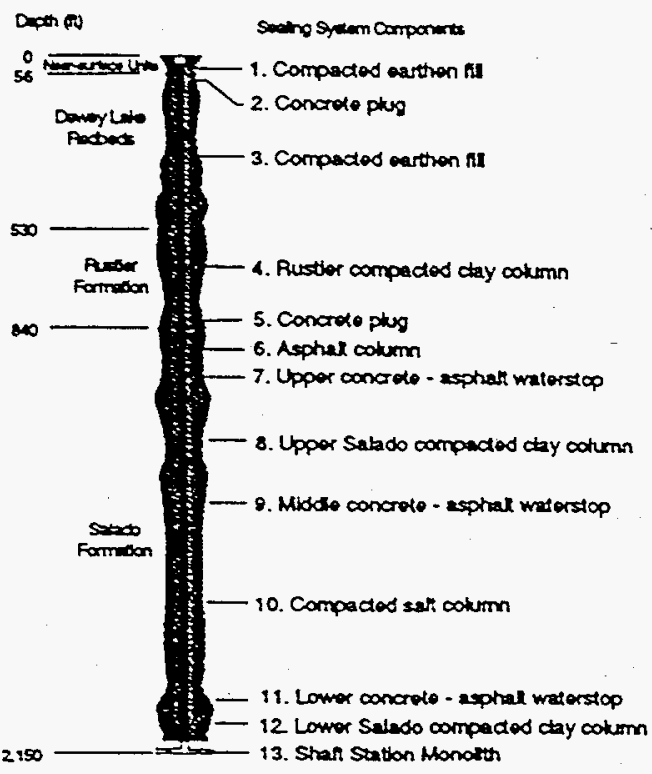
function of time and depth.

\section{Crushed-Salt Deformation Mechanisms}

Multiple deformation mechanisms control the densification of crushed salt for the emplacement processes and range of conditions expected at the WIPP. During emplacement in the shaft, crushed salt will be dynamically compacted with small amounts of added moisture (less than 2 percent by weight) to a fractional density of about 90 percent of intact salt. During dynamic compaction, the densification of the crushed salt will occur through particle rearrangement, cataclasis, and plastic yield. These instantaneous processes provide a dense, locked-up aggregate.

Further densification occurs over time through compactional loading on the crushed-salt column caused by creep of the host salt formation and inward movement of the shaft surface. As the crushed salt is loaded, the principal densification mechanisms are dislocation creep and fluid-phase diffusional creep (grain boundary diffusional pressure solutioning). Without the added moisture 
during construction of the crushed-salt seal component, the importance of the diffusional creep mechanism would diminish.

The dislocation creep of salt is defined in terms of three dislocation mechanisms involving dislocation climb, an undefined (but experimentally and empirically well established) mechanism, and dislocation glide (Munson et al., 1989). The presence of the liquid phase leads to the additional deformational processes characterized by stress-induced dissolution, diffusion, and precipitation. The total creep rate is controlled by the slowest of these serial processes. The grain boundary diffusional pressure solution mechanism dramatically enhances the densification rate in crushed salt (Spiers and Schutjens, 1990).

\section{Structural Models}

Intact salt was assumed to be govemed by the multimechanism deformation coupled fracture (MDCF) model (Chan, 1993). This model is an extension of the Munson-Dawson (M-D) creep model (Munson et al., 1989) that includes a continuous definition of the evolution of damage and healing of salt. The evolutionary equations describing the MDCF model for WIPP are described in detail by DeVries (1994). The creep consolidation model used is the revised Sjaardema-Krieg model. The equations describing this model are reported by Callahan et al. (1995).

The fluid in the crushed salt was assumed to behave as a linear elastic material in which the fluid pressure is related to the volumetric strain through the bulk modulus as:

$$
P=\operatorname{MIN}\left\{P_{0}+K\left(1-V / V_{0}\right), P_{\max }\right\}
$$

where:

$$
\begin{aligned}
P & =\text { fluid pressure }(\mathrm{MPa}) \\
P_{0} & =\text { initial fluid pressure }(\mathrm{MPa}) \\
K & =\text { fluid bulk modulus }(\mathrm{MPa}) \\
V & =\text { current volume of crushed salt }\left(\mathrm{m}^{3}\right) \\
V_{0} & =\text { initial volume (based on } 90 \text { percent fractional density) }\left(\mathrm{m}^{3}\right) \\
P_{\max } & =\text { maximum fluid pressure }(\mathrm{MPa}) .
\end{aligned}
$$

A model was developed that relates permeability and density of crushed salt. Laboratory measurements indicate that the permeability decreases as density increases (Figure 2). Furthermore, the density of the crushed salt in the column seal will increase with time during reconsolidation because of creep of the surrounding salt. It was determined that a linear model relating permeability 
(transformed into logarithmic space) and fractional density was a good approximation to the laboratory data over the range of densities tested. A linear least-squares fit was performed using the following model:

$$
\log (k)=m \rho+b
$$

where $k$ is intrinsic permeability with units of $\mathrm{m}^{2}, p$ is the dimensionless fractional density based on an intact salt density of $2,160 \mathrm{~kg} / \mathrm{m}^{3}$, and $m$ and $b$ are fitting parameters determined to be $-54.885 \mathrm{~m}^{2}$ and $34.613 \mathrm{~m}^{2}$, respectively. For a fractional density of one (i.e., density equivalent to intact salt), the model predicts a permeability of $5.34 \times 10^{-21} \mathrm{~m}^{2}$, which is within an order of magnitude of the assumed permeability for intact salt; i.e., $1.0 \times 10^{-21} \mathrm{~m}^{2}$.

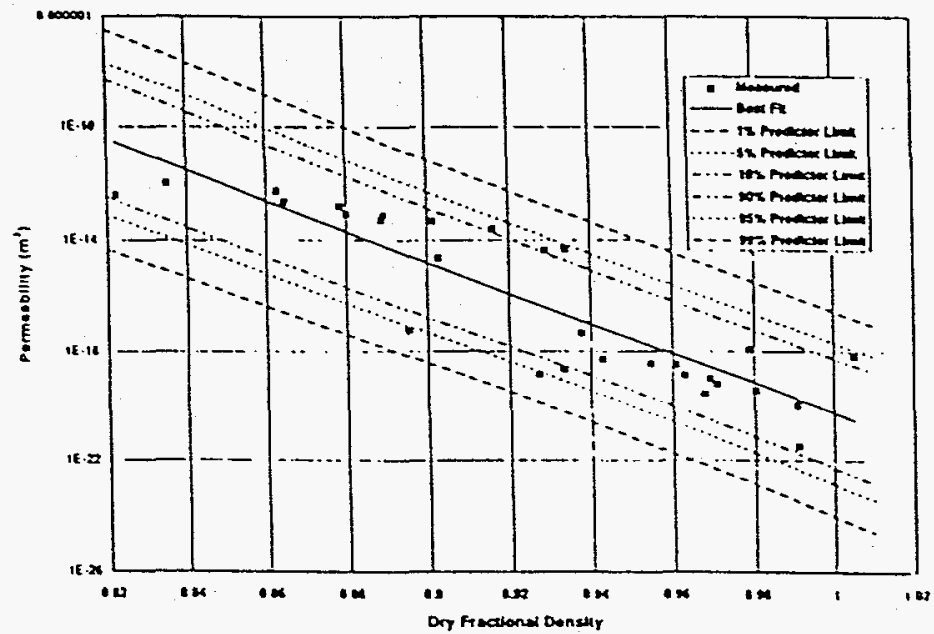

Figure 2. Measured and Predicted Permeability Versus Dry Fractional Density for the Compacted Crushed-Salt Column.

In the structural analysis, models representative of a single depth were used. These models are axisymmetric representations of the AIS and the surrounding intact salt. Conditions of plane strain are assumed with respect to depth. For times less than -50 years, the in situ stress state is assumed to be isotropic and is calculated based on the weight of the overburden. The shaft is assumed to be excavated at time $=-50$ years and left open for 50 years. The shaft is then instantaneously backfilled with crushed salt at a fractional density of 90 percent. The crushed-salt density is calculated as a function of time for 500 years following emplacement of the seal. A representative conceptual model used in this analysis is shown in Figure 3.

Three models (depths) were considered: $430 \mathrm{~m}, 515 \mathrm{~m}$, and $600 \mathrm{~m}$, representative of the initial stress conditions at the top, middle, and bottom of the crushed-salt seal. Fluid pressures considered were 0,2 , and $4 \mathrm{MPa}$. The numerical calculations were performed using the finite element program 
SPECTROM-32 Version 4.06 (Callahan, 1994). The material models described above are implemented in this program. A simple modification to the program was required to include the variable $P_{\max }$ (Equation 1) used in the linear elastic fluid model. The program was used to calculate the crushed-salt density as a function of depth, fluid pore pressures, and time after emplacement. Figure 4(a) shows a specific result; that is, the crushed-salt fractional density as a function of time after emplacement at the top, middle, and bottom of the seal for a fluid pore pressure of $2 \mathrm{MPa}$.

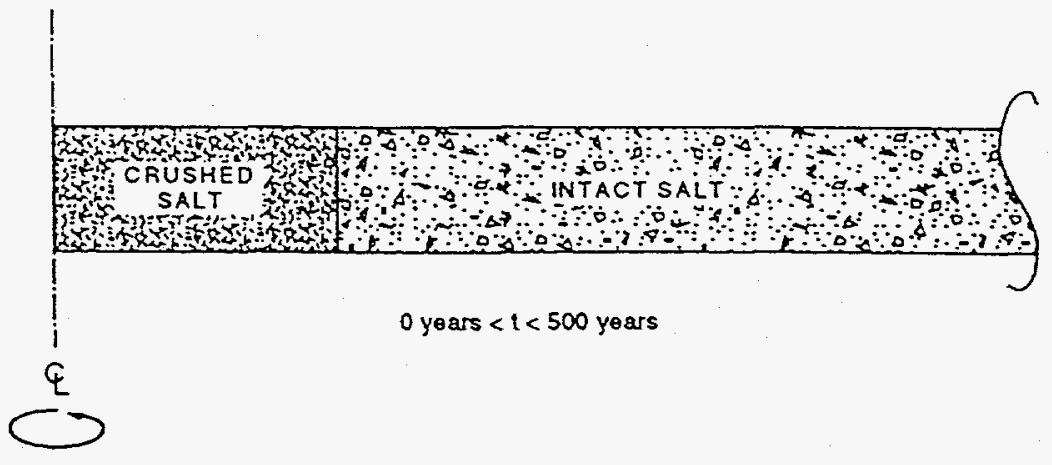

Figure 3. Conceptual Model Used to Calculate Crushed-Salt Density.

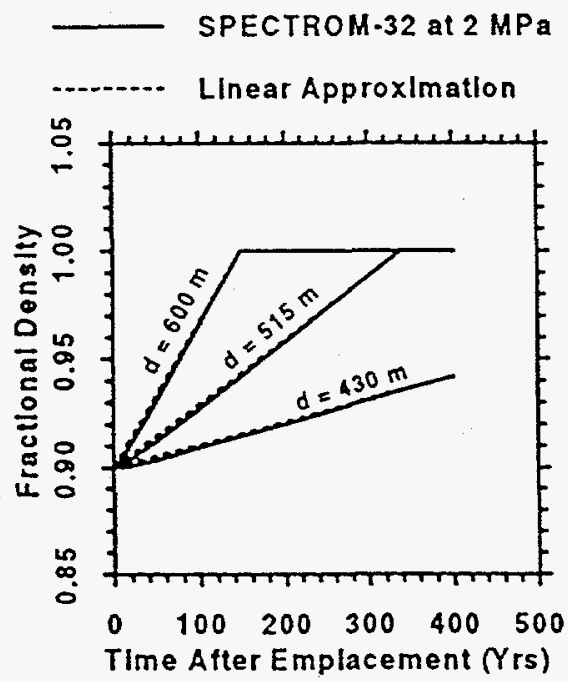

(a)

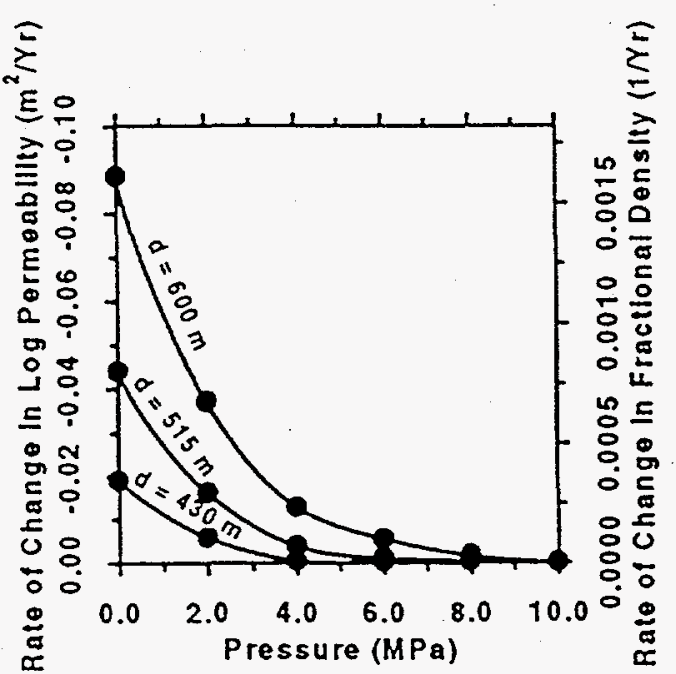

(b)

Figure 4. (a) Calculated Fractional Density Versus Time at Three Depths (d), and (b) Rate of Change in Permeability and Fractional Density Versus Pressure.

By making a linear approximation to the calculated densities as shown in Figure 4(a), the average rate of change in density can be determined over the time periods in which consolidation is occurring at the various depths. Figure $4(\mathrm{~b})$ 
presents the results in terms of the average rate of change in fractional density (on the right axis) versus pressure at the three depths considered. (Points beyond $4 \mathrm{MPa}$ were extrapolated.) Using Equation 2, the left axis in Figure 4(b) gives the rate of change in log permeability versus pressure. These results indicate that the time required to reconsolidate crushed salt decreases with depth and increases with fluid pressure. Furthermore, these results illustrate that consolidation of the crushed salt is effectively terminated at fluid pressures greater than $4 \mathrm{MPa}$.

\section{Fluid Flow Model}

Calculations of fluid pressures were carried out using a fluid flow model and the rate of change in permeability versus pressure and depth data determined by the structural model. Pore pressures in the crushed-salt seal will increase after seal emplacement due to three possible sources of fluid movement into the seal: (1) brine flow down the shaft from water bearing strata above, (2) gas flow up the shaft due to gas generation in the repository below, and (3) brine flow toward the shaft from the host Salado Formation due to pressure gradients created during the period the shaft is open to atmospheric pressure. The fluid flow model was implemented with TOUGH28W Version 2.02, a numerical simulation program for multidimensional coupled fluid and heat flows of multiphase, multicomponent fluid mixtures in porous and fractured media. This is a modified version of TOUGH2 (Pruess, 1991) which includes the ability to specify a rate of change in material permeability as a function of depth and fluid pressure.

The axisymmetric grid implementing the model geometry and boundary conditions is depicted in Figure 5. The leftmost (inner) model boundary was considered to be noflow since this is the line of symmetry at the center of the shaft. The rightmost model boundary was assumed to be a constant pressure boundary at hydrostatic equilibrium relative to $12.5 \mathrm{MPa}$ near the base of the repository. Initial conditions were established by running a 50-year simulation with shaft pressure held at atmospheric conditions representative of an open shaft. Gas generation from corrosion of waste forms in the repository was simulated by applying a time-varying gas pressure boundary condition at the base of the shaft. The maximum gas pressure reached was

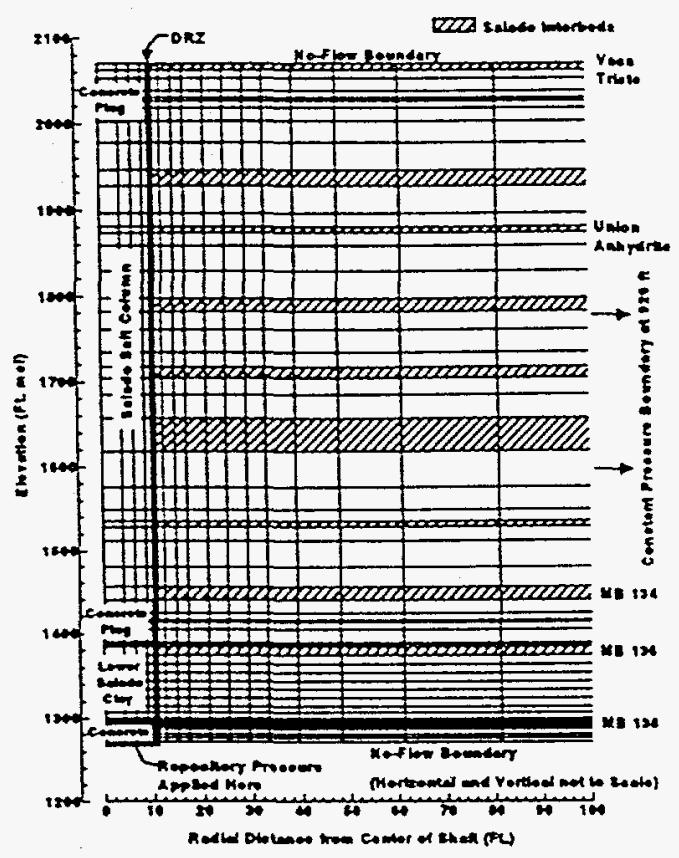

Figure 5. Fluid Flow Model Grid. 
$14 \mathrm{MPa}$ at 200 years. Material permeabilities used in the model are shown in Table 1 (Repository Isolation Systems Department, 1996).

Crushed-salt permeability data from Figure 4(b) was input to the TOUGH28W model as a table of rate of change in $\log$ permeability values as a function of pressure and depth. Model calculated vertical permeability profiles in the compacted salt column at several times following seal emplacement are shown in Figure 6(a). Figure 6 (b) shows composite length averaged salt column permeability as a function of time after seal emplacement. Figure 6(a) shows that the permeability has decreased to a minimum value of $6.3 \times 10^{-21}$ over a portion of the base of the salt column in 100 years and shows little further reduction of permeability over the period from 100 to 200 years. The figure generally shows lower permeability near the bottom of the salt column where the consolidation rate is higher and relatively higher permeability near the top of the salt column where the consolidation rate is lower. After 100 years, pressure increases throughout the column have almost completely stopped the consolidation process.

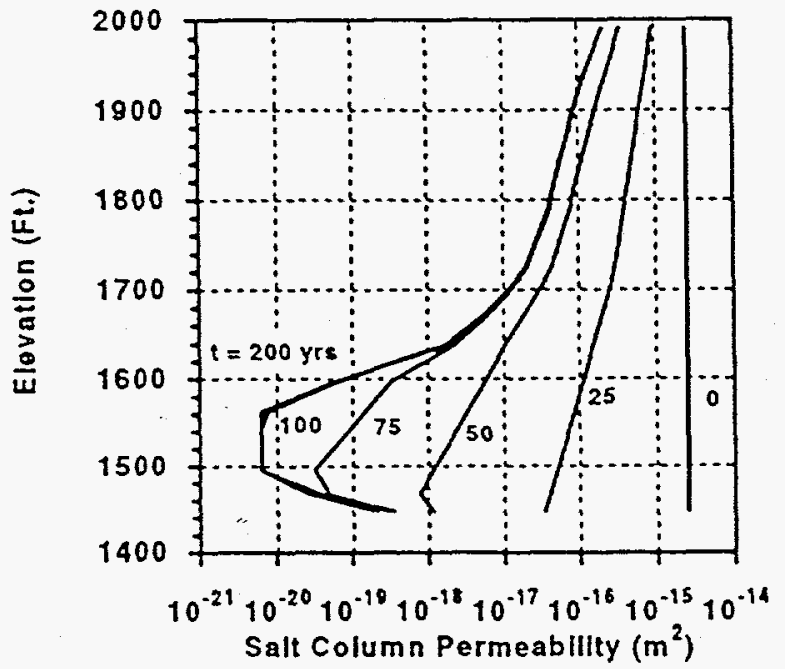

(a)

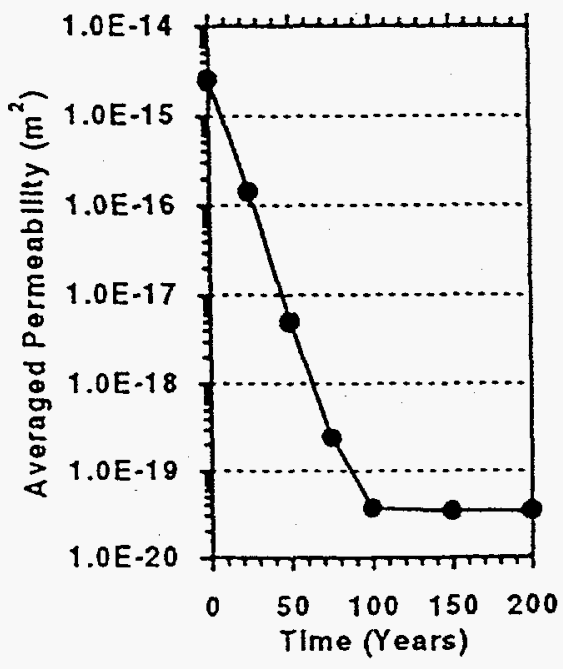

(b)

Figure 6. (a) Calculated Vertical Profiles of Crushed Salt Permeability, and (b) Length Averaged Seal Permeability Versus Time. 
A small region, from an elevation of $439 \mathrm{~m}(1,440 \mathrm{ft})$ to about an elevation of $457 \mathrm{~m}(1,500 \mathrm{ft})$, at the base of the salt column showed less reconsolidation at times ranging from 50 to 200 years than the region immediately above it due to the pressure influence of the repository. Figure 6(a) also shows that for times greater than about 50 years, consolidation in the upper one-half of the salt column was significantly slowed because of repressurization through the relatively high permeability Union Anhydrite $\left(1.0 \times 10^{-18} \mathrm{~m}^{2}\right)$. Model results were nearly identical for repository pressure conditions reaching $7 \mathrm{MPa}$ and $14 \mathrm{MPa}$, indicating little sensitivity to this parameter. Figure $6(\mathrm{~b})$ shows that the length-averaged crushedsalt-column permeability reaches approximately $3.3 \times 10^{-20} \mathrm{~m}^{2}$ within 100 years after emplacement and remains unchanged thereafter, providing an excellent low permeability long-term seal.

\section{References}

Callahan, G. D., 1994. SPECTROM-32: A Finite Element Thermomechanical Stress Analysis Program Version 4.06, RSI-0531, prepared by RE/SPEC Inc., Rapid City, SD, for Sandia National Laboratories, Albuquerque, NM.

Callahan, G. D., M. C. Loken, L. D. Hurtado, and F. D. Hansen, 1995. "Evaluation of Constitutive Models for Crushed Salt," Proceedings, $4^{\text {th }}$ Conference on the Mechanical Behavior of Salt, Montreal, Quebec, Canada, June 17-18, 1996, Montreal, Quebec, Canada.

Chan, K. S., 1993. Time Dependent Interface of Bed Separation Fracture Process in Bedded Natural Salt Deposits, Monthly Technical Report No. Fy'93-8, prepared by Southwest Research Institute, San Antonio, TX, for Sandia National Laboratories, Albuquerque, NM.

DeVries, K. L., 1994. Prediction of Damage Around the WIPP Room D Experiment, Calculation File 325/3.3/01, prepared by RE/SPEC Inc., Rapid City, SD, for Sandia National Laboratories, Albuquerque, NM.

Munson, D. E., A. F. Fossum, P. E. Senseny, 1989. Advances in Resolution of Discrepancies Between Predicted and Measured in Situ WIPP Room Closures, SAND88-2984, Sandia National Laboratories, Albuquerque, NM.

Pruess, K. 1991. TOUGH2- A General-Purpose Numerical Simulator for Multiphase Fluid and Heat Flow, LBL-29400, Earth Sciences Division, Lawrence Berkeley Laboratory, Berkeley, CA.

Repository Isolation Systems Department, 1996. Waste Isolation Pilot Plant Shaft Sealing System Compliance Submittal Design Report, SAND96-1326, Sandia National Laboratories, Albuquerque, NM.

Spiers, C. J. and P. M. T. M. Schutjens, 1990. Densification of Crystalline Aggregates by Fluid-Phase Diffusional Creep, Deformation Process in Minerals, Ceramics and Rocks, D. J. Barber and P. D. Meredith (eds.), Unwin Hyman, London.

\footnotetext{
*Sandia is a multiprogram laboratory oeprated by the Sandia Corporation, a Lockheed Martin Company, for the United States Department of Energy under Contract DE-ACO494AL85000.
} 